\title{
Impact of Socioeconomic, Behavioral and Psychological Factors for Children's Self-Reported Oral Symptoms
}

\author{
Seon-Hui Kwak ${ }^{1}$ and Bo-Mi Shin ${ }^{1,2 \dagger}$ \\ ${ }^{1}$ Department of Dental Hygiene, College of Dentistry and ${ }^{2}$ Research Institute of Oral Science, Gangneung-Wonju National \\ University, Gangneung 25457, Korea
}

This study investigated factors affecting the subjective experience of oral symptoms among 2,285 elementary school students in the fourth and sixth grades using the Korean survey on the Health of Youth and Children in 2010. After conducting chi-square and Mann-Whitney U tests, we performed multiple logistic regression analysis to determine the factors affecting children's experience of oral symptoms. We found that the factors most frequently associated with the subjective experience of more oral symptoms were lower tooth brushing frequency, greater intake of foods that cause dental caries, higher stress levels, and lower levels of support from friends. In conclusion, determinants of children's oral health, such as children's oral health behaviors and psychological factors must be considered in a multifaceted approach to developing programs to promote oral health among children.

Key Words: Child, Oral symptom experiences, Psychological factor, Social determinants of health

\section{Introduction}

The school-age years represent an important period during which primary teeth are replaced by permanent teeth, the rate of dental caries is high, and basic oral health behaviors such as oral health management and eating habits develop and become permanent ${ }^{1)}$. Korea has been running various oral health projects, which have lowered the decayed (DMFT), index among children aged 12 years in the last 10 years, from 3.3 in 2000 to 2.1 in $2010^{2)}$. However, the oral health status of Korean children is still considered poor compared with that of children in Denmark (0.7), England (0.7), and other developed countries ${ }^{3)}$, and dental caries is the most common chronic disorder affecting a large number of children in Korea.

Dental caries is a multifactorial disorder affected by genetic, biological, behavioral, and social factors ${ }^{4)}$. Numerous studies investigating the risk factors of dental caries have pointed out the limits not explained by biological and behavioral factors on oral health at the individual level, and have assessed risk factors from many aspects ${ }^{5,6}$. Fisher-Owens et al. ${ }^{5)}$ looked at the influence of individual, family, and community levels on oral health outcomes. These authors described genetic and biological factors, the social environment, the physical environment, health behaviors, and dental and medical care as the five key domains of determinants of oral health. They reviewed social factors at the family level, including stress and support from family and friends, and explained that psychological factors significantly influence children's oral health.

Korean children are experiencing high levels of psychosocial stress. This not only arises in the normal process of development but also in academic life, which is strongly emphasized in Korea where "education fever" is ongoing, and also from reduced support from family and 
school as a result of changes in the social environment. According to a survey on the comprehensive situation of Korean children conducted in $2013^{7)}$, the most common cause of stress among Korean children is academic challenges. In that survey, $50.5 \%$ of children scored 3 or more out of 4 on a scale measuring the level of academic stress, and $60.3 \%$ reported a level of life satisfaction in the middle range or above ( 6 points), thus marking the highest and lowest proportions among the 30 countries investigated by the United Nations Children's Fund, respectively. Bullying is the most common and serious form of school violence experienced by students (24.4\%), which aggravates psychological anxiety and social isolation among children starting from when they enroll in elementary school ${ }^{8)}$. Duncan et al. ${ }^{9)}$ explained that social isolation in children is associated with unhealthy behaviors and can act as a health risk factor, and that psychosocial factors in children may more negatively affect children's oral health than in the past.

The association between stress and oral health has been extensively investigated. In Korea, Shin ${ }^{10)}$ used a structured stress-measuring instrument to study the association of stress among elementary school children with oral health behavior and status; Park et al. ${ }^{11)}$ reported a negative correlation between daily life stress and oral health status among adolescents; and Jung ${ }^{12)}$ reported that the higher the level of perceived stress among adolescents, the lower their quality of life related to oral health. A number of studies that considered psychosocial factors, such as self-worth and support from family and friends, have investigated the significance of associations among the level of stress in adults, self-worth, oral health behaviors, and oral health-related quality of life ${ }^{13,14)}$; however, very few studies have used psychological variables related to children. Therefore, it is necessary to investigate the effects of psychological factors on children's oral health after considering psychosocial and oral health behavioral factors, which are determinants of oral health, using indices that reflect various psychological characteristics including stress.

In the present study, we obtained a sample of subjects that is representative of the entire population of children in Korea, using data from the Korea Adolescent Health
Survey (2010), and we investigated the effects of psychosocial, oral health behavioral, and psychological factors on the subjective experience of oral symptoms among children.

\section{Materials and Methods}

\section{Research data and subjects}

In this study, we used data from the Korea Adolescent Health Survey (2010), a sample survey conducted as part of a comprehensive survey of Korean youth conducted between June 2010 and October 2010. The Statistical Yearbook of Education (2009) was used as the sampling frame to calculate sample size based on the population distributions of elementary, middle, and high school students in 15 provinces of Korea, excluding Jeju province. Sample schools were selected by stratified random cluster sampling, and systematic sampling was performed using grade level as the primary sampling unit and students as the secondary sampling unit. Trained examiners visited the selected schools and conducted a group interview using structured questionnaires. The total number of participants in the survey was 9,844, and the questionnaire return rate was $90.7 \%$. A total of 2,285 elementary school students in grades $4 \sim 6$, for whom the investigation was complete, were selected as the final participants. This study was conducted following its approval by the Institutional Review Board of Gangneung-Wonju National University (IRB no. GWNU IRB-2016-08).

\section{Research variables}

The subjective experience of oral symptoms was used as a binary dependent variable whose value was determined according to whether one or more of the following symptoms were experienced: tooth cracking or fracture in the last one year, throbbing pain when eating cold or hot food, gum pain or bleeding, throbbing pain in the tongue or inner cheek, and bad breath.

Sex and grade level were used as demographic variables of the students. Family composition was classified as living with both parents, living with one parent, and living with grandparents. Level of academic performance was classified as very poor, poor, average, good, and very 
good. High, middle, and low subjective economic levels were used as socioeconomic variables. Oral behavioral variables included the frequency of brushing teeth after lunch in the last one week ( 5 times or more per week/4 times or less per week) and the frequency of consuming carbonated beverages, snacks, chocolate, and sweets (3 times or more per week/2 times or less per week).

The psychological factors assessed included stress level as an intrapersonal maladaptive psychological factor (12 questions), and level of self-worth as an adaptive psychological factor (5 questions). Social support factors included support from family (5 questions) and support from friends ( 3 questions). Details of the questions in each domain of the questionnaire are shown in Table 1. The psychological variables were rated from 1 point (not at all) to 4 points (very true), and the mean value was calculated for each factor and compared with other mean values. The reliability and validity ${ }^{15)}$ of the psychological factors used in this study were verified using the Delphi method ${ }^{16)}$. Two meetings were held in which 10 experts examined psychological factors selected from the Korea Adolescent Health Survey (2010); factors that scored 4 or more points or with a positive response rate of $75 \%$ or more were selected.

\section{Method of analysis}

A chi-square test was used to analyze the association between subjective experience of oral symptoms, and general, socioeconomic, and oral behavioral factors. A p-value less than 0.001 was found when a Kolmogorov-Smirnov test was performed to test the normality of the psychological variables; therefore, the assumption of normality was not satisfied. As a result, a Mann-Whitney $\mathrm{U}$ test was performed to study the association between subjective experience of oral symptoms and psychological factors. A multiple logistic regression analysis was used to study the effects of the related factors on subjective experience of oral symptoms. Multicollinearity was suspected among the psychological variables, stress, self-worth, support from family, and support from friends; as a result, a correlation analysis was carried out, which showed correlation coefficients less than 0.4 . The variance inflation factor was found to be less than 1; as a result, multicollinearity was deemed nonexistent. Therefore, the psychological variables were included in the regression model. The analysis results were expressed as odds ratios (ORs), and 95\% confidence intervals. The statistical analyses were performed with IBM SPSS Statistics ver. 20.0 (IBM Co., Armonk, NY, USA).

\section{Results}

\section{Participant characteristics}

General characteristics of the study participants are shown in Table 2. Of the total 2,285 participants, 50.5\% were male, and $49.5 \%$ were female. With respect to oral symptoms, toothaches were the most common $(22.4 \%)$ whereas mouth ulcers were the least common $(6.6 \%)$. The rates of tooth fracture and bad breath were significantly higher among male students than among female students. The rates of toothache, bleeding gums, and mouth ulcer increased with grade level. The rate of tooth fracture was highest among fourth graders and that of bad breath was highest among fifth graders $(\mathrm{p}<0.05)$.

\section{Experience of oral symptoms according to socioe-} conomic characteristics and oral health behaviors Oral symptoms according to demographic, socioeco-

Table 1. Psychological Factor Variables

\begin{tabular}{|c|c|c|c|}
\hline Item & Classification & $\mathrm{n}$ & Variable \\
\hline Maladaptive psychological factor & Stress & 12 & Stress related to home, school, friends, appearance, material \\
\hline Adaptive psychological factor & Self-esteem & 5 & $\begin{array}{l}\text { Value for oneself, good character, cooperation, positive attitude, } \\
\text { satisfaction with oneself }\end{array}$ \\
\hline Social support & Family support & 5 & $\begin{array}{l}\text { Family concord, spending time with family, dependence on } \\
\text { family, friendliness, interest }\end{array}$ \\
\hline Social support & Friend support & 3 & $\begin{array}{l}\text { Talking with friends, spending time with friends, and attitude } \\
\text { when I'm with friends }\end{array}$ \\
\hline
\end{tabular}


Table 2. Difference among the Subject in Oral Symptoms according to General Characteristics

\begin{tabular}{ccccccc}
\hline Variable & $\mathrm{n}(\%)$ & Tooth fracture $(\%)$ & Toothache $(\%)$ & Bleeding gum $(\%)$ & Ulceration $(\%)$ & Bad breath $(\%)$ \\
\hline Total & $2,285(100.0)$ & 11.6 & 22.4 & 14.6 & 6.6 & 11.9 \\
Gender & & & & & & \\
Boy & $1,155(50.5)$ & 13.6 & 22.1 & 14.2 & 5.7 & 14.2 \\
Girl & $1,130(49.5)$ & 9.5 & 22.6 & 15.0 & 7.4 & 9.6 \\
p-value & & 0.002 & 0.786 & 0.579 & 0.085 & 0.001 \\
Grade & & & & & & \\
4th & $703(30.8)$ & 14.9 & 16.5 & 13.8 & 4.8 & 12.7 \\
5th & $776(34.0)$ & 9.8 & 23.8 & 12.6 & 6.3 & 14.0 \\
6th & $806(35.3)$ & 11.0 & 26.1 & 17.1 & 8.3 & 9.2 \\
p-value & & 0.031 & $<0.001$ & 0.032 & 0.023 & 0.009 \\
\hline
\end{tabular}

By chi-square test.

Table 3. Oral Symptom Experience by Socioeconomic and Oral Health Behavior Factors

\begin{tabular}{|c|c|c|c|c|}
\hline Variable & Total & 1 or more experience & No experience & p-value \\
\hline Total & $2,285(100.0)$ & $1,061(46.4)$ & $1,224(53.6)$ & \\
\hline \multicolumn{5}{|l|}{ Demographic factors } \\
\hline \multicolumn{5}{|l|}{ Gender } \\
\hline Girl & $1,130(49.5)$ & $548(48.5)$ & $582(51.5)$ & 0.051 \\
\hline Boy & $1,155(50.5)$ & $513(44.4)$ & $642(55.6)$ & \\
\hline \multicolumn{5}{|l|}{ Grade } \\
\hline 4 th & $703(30.8)$ & $309(44.0)$ & $394(56.0)$ & 0.283 \\
\hline 5 th & $776(34.0)$ & $370(47.7)$ & $406(52.3)$ & \\
\hline 6 th & $806(35.3)$ & $382(47.4)$ & $424(52.6)$ & \\
\hline \multicolumn{5}{|l|}{ Family members } \\
\hline Two-parent family & $2,004(87.7)$ & $926(46.2)$ & $1,078(53.8)$ & 0.564 \\
\hline Single parent/grandparents family & $281(12.3)$ & $135(48.0)$ & $146(52.0)$ & \\
\hline \multicolumn{5}{|l|}{ Academic achievement } \\
\hline High & 973 (42.6) & $425(43.7)$ & $548(56.3)$ & $<0.001$ \\
\hline Middle & $982(43.0)$ & $451(45.9)$ & $531(54.1)$ & \\
\hline Low & $330(14.4)$ & $185(56.1)$ & 145 (43.9) & \\
\hline \multicolumn{5}{|l|}{ Socio-economic factors } \\
\hline \multicolumn{5}{|l|}{ Income status } \\
\hline High & $1,262(55.2)$ & $548(43.4)$ & $714(56.6)$ & $<0.001$ \\
\hline Middle & $870(38.1)$ & $420(48.3)$ & $450(51.7)$ & \\
\hline Low & $153(6.7)$ & $93(60.8)$ & $60(39.2)$ & \\
\hline \multicolumn{5}{|l|}{ Oral health behavior factor } \\
\hline \multicolumn{5}{|l|}{ Toothbrushing after lunch time } \\
\hline 5 or more times $(/ \mathrm{wk})$ & $954(41.8)$ & $413(43.3)$ & $541(56.7)$ & 0.011 \\
\hline 4 times and less (/wk) & $1,331(58.2)$ & $648(48.7)$ & $683(51.3)$ & \\
\hline \multicolumn{5}{|l|}{ Drinking carbonated beverage } \\
\hline 2 times and less $(/ \mathrm{wk})$ & $2,096(91.7)$ & $957(45.7)$ & $1,139(54.3)$ & 0.013 \\
\hline 3 or more times $(/ \mathrm{wk})$ & $189(8.3)$ & $104(55.0)$ & $85(45.0)$ & \\
\hline \multicolumn{5}{|l|}{ Snack intakes } \\
\hline 2 times and less (/wk) & $1,805(79.0)$ & $823(45.6)$ & $982(54.4)$ & 0.119 \\
\hline 3 or more times (/wk) & $480(21.0)$ & $238(49.6)$ & $242(50.4)$ & \\
\hline \multicolumn{5}{|l|}{ Eating confectionary } \\
\hline 2 times and less (/wk) & $1,546(67.7)$ & $669(43.3)$ & 877 (56.7) & 0.001 \\
\hline 3 or more times (/wk) & 739 (32.3) & $392(53.0)$ & $347(47.0)$ & \\
\hline
\end{tabular}

Values are presented as $\mathrm{n}(\%)$.

By chi-square test. 
nomic, and oral health behavioral factors are listed in Table 3. The rate of having more than one oral symptom was $46.4 \%$, and the rate of experiencing oral symptoms was higher among male participants than females, but not to a statistically significant degree $(p>0.05)$. The rate of experiencing oral symptoms was $60.8 \%$ for participants with low subjective economic level, higher than those with middle $(48.3 \%)$ and high $(43.4 \%)$ economic levels $(\mathrm{p}<$ 0.001). The rate of experiencing oral symptoms was higher among participants who brushed their teeth 4 times or less per week than those who consumed carbonated drinks, chocolate, and sweets 3 times or more per week $(\mathrm{p}<0.05)$.

\section{Experience of oral symptoms according to levels of} stress, self-worth, and social support

Oral symptoms according to levels of stress, self-worth, and social support are listed in Table 4. Students who experienced more than one oral symptom (tooth fracture, toothache, gum bleeding, mouth ulcer, and bad breath) had higher stress levels and lower levels of self-worth and support from family and friends than participants who did not experience any oral symptoms $(\mathrm{p}<0.001)$. A significant difference in stress levels was observed according to the type of oral symptom. Students who had previously had mouth ulcers had the highest level of perceived stress of 1.80 points. Students who had previously had toothaches or bad breath had low levels of self-worth and support from family and friends.

\section{Effects of socioeconomic characteristics, oral health behavior, and psychological factors on subjective experience of oral symptoms}

The associations of subjective experience of oral symptoms with socioeconomic, oral health behavioral, and psychological factors, and how these factors affect children's experience of oral symptoms were studied; the

Table 4. Oral Symptom Experience by Level of Psychological Factors

\begin{tabular}{|c|c|c|c|c|}
\hline Variable & Stress & Self-esteem & Family support & Friend support \\
\hline Total & $1.54 \pm 0.47$ & $2.85 \pm 0.74$ & $3.29 \pm 0.66$ & $3.29 \pm 0.69$ \\
\hline \multicolumn{5}{|c|}{ Oral symptoms experience } \\
\hline No & $1.44 \pm 0.42$ & $2.94 \pm 0.74$ & $3.38 \pm 0.65$ & $3.37 \pm 0.64$ \\
\hline 1 or more & $1.64 \pm 0.51$ & $2.75 \pm 0.73$ & $3.19 \pm 0.67$ & $3.20 \pm 0.72$ \\
\hline $\mathrm{p}$-value & $<0.001$ & $<0.001$ & $<0.001$ & $<0.001$ \\
\hline \multicolumn{5}{|l|}{ Tooth fracture } \\
\hline No & $1.53 \pm 0.47$ & $2.86 \pm 0.74$ & $3.30 \pm 0.67$ & $3.31 \pm 0.68$ \\
\hline Yes & $1.62 \pm 0.51$ & $2.78 \pm 0.77$ & $3.25 \pm 0.62$ & $3.18 \pm 0.75$ \\
\hline p-value & 0.002 & 0.072 & 0.090 & 0.016 \\
\hline \multicolumn{5}{|l|}{ Toothache } \\
\hline No & $1.49 \pm 0.45$ & $2.88 \pm 0.75$ & $3.34 \pm 0.65$ & $3.32 \pm 0.67$ \\
\hline Yes & $1.69 \pm 0.52$ & $2.76 \pm 0.72$ & $3.14 \pm 0.70$ & $3.19 \pm 0.72$ \\
\hline p-value & $<0.001$ & $<0.001$ & $<0.001$ & $<0.001$ \\
\hline \multicolumn{5}{|l|}{ Bleeding gum } \\
\hline No & $1.51 \pm 0.45$ & $2.87 \pm 0.74$ & $3.31 \pm 0.66$ & $3.31 \pm 0.67$ \\
\hline Yes & $1.72 \pm 0.57$ & $2.74 \pm 0.78$ & $3.21 \pm 0.70$ & $3.18 \pm 0.78$ \\
\hline p-value & $<0.001$ & 0.003 & 0.013 & 0.009 \\
\hline \multicolumn{5}{|l|}{ Ulceration } \\
\hline No & $1.52 \pm 0.46$ & $2.86 \pm 0.74$ & $3.31 \pm 0.66$ & $3.30 \pm 0.69$ \\
\hline Yes & $1.80 \pm 0.56$ & $2.76 \pm 0.78$ & $3.09 \pm 0.74$ & $3.20 \pm 0.69$ \\
\hline p-value & $<0.001$ & 0.073 & $<0.001$ & 0.046 \\
\hline \multicolumn{5}{|l|}{ Bad breath } \\
\hline No & $1.52 \pm 0.47$ & $2.88 \pm 0.74$ & $3.31 \pm 0.66$ & $3.32 \pm 0.67$ \\
\hline Yes & $1.67 \pm 0.50$ & $2.66 \pm 0.75$ & $3.14 \pm 0.69$ & $3.11 \pm 0.78$ \\
\hline p-value & $<0.001$ & $<0.001$ & $<0.001$ & $<0.001$ \\
\hline
\end{tabular}

Values are presented as mean \pm standard deviation.

By Mann-Whitney U test. 
results are shown in Table 5. In a basic model that included demographical and socioeconomic factors (Model 1), the OR for experiencing oral symptoms was twice as high for participants with low subjective socioeconomic status as for those with high subjective socioeconomic status $(\mathrm{p}<$ 0.05). In Model 2, which was created by adding oral behavior factors to the basic model, socioeconomic level was still significantly associated with experience of oral symptoms $(p<0.05)$. The OR for experiencing oral symptoms was 1.19 times higher for participants who brushed their teeth 4 times or less per week than for those who did so 5 times or more per week; also, the OR was 1.38 times higher for participants who consumed chocolate and sweets 3 times or more per week than those who did so twice or less per week ( $\mathrm{p}<0.05$ ). In Model 3 , which included psychological factors in addition to the variables in the basic model, no association was found between socioeconomic level and experience of oral symptoms, and the risk for subjective oral symptoms increased 2.13-fold when the participant's level of perceived stress was high $(\mathrm{p}<0.05)$. In the final model, Model 4 , which included all the related factors, tooth brushing after lunch,

Table 5. Factors Affecting the Oral Symptom Experience

\begin{tabular}{|c|c|c|c|c|}
\hline \multirow{2}{*}{ Predictors } & \multicolumn{4}{|c|}{ Odds ratio (95\% confidence interval) } \\
\hline & Model 1 & Model 2 & Model 3 & Model 4 \\
\hline \multicolumn{5}{|l|}{ Demographic factors } \\
\hline \multicolumn{5}{|l|}{ Gender } \\
\hline Girl & 1.00 & 1.00 & 1.00 & 1.00 \\
\hline Boy & $1.19(1.02 \sim 1.40)^{*}$ & $1.21(1.03 \sim 1.42)^{*}$ & $1.28(1.08 \sim 1.51)^{* *}$ & $1.30(1.10 \sim 1.54)^{* *}$ \\
\hline \multicolumn{5}{|l|}{ Grade } \\
\hline 4 th & 1.00 & 1.00 & 1.00 & 1.00 \\
\hline 5 th & $1.07(0.88 \sim 1.30)^{\mathrm{NS}}$ & $1.07(0.87 \sim 1.30)^{\mathrm{NS}}$ & $1.08(0.88 \sim 1.33)^{\mathrm{NS}}$ & $1.05(0.85 \sim 1.29)^{\mathrm{NS}}$ \\
\hline 6 th & $1.02(0.84 \sim 1.23)^{\mathrm{NS}}$ & $1.03(0.84 \sim 1.25)^{\mathrm{NS}}$ & $0.95(0.77 \sim 1.17)^{\mathrm{NS}}$ & $0.89(0.72 \sim 1.09)^{\mathrm{NS}}$ \\
\hline \multicolumn{5}{|l|}{ Academic achievement } \\
\hline High & 1.00 & - & - & 1.00 \\
\hline Middle & $1.07(0.90 \sim 1.27)^{\mathrm{NS}}$ & & & $0.98(0.81 \sim 1.18)^{\mathrm{NS}}$ \\
\hline Low & $1.57(1.23 \sim 2.01)^{* * *}$ & & & $1.16(0.88 \sim 1.52)^{\mathrm{NS}}$ \\
\hline \multicolumn{5}{|l|}{ Socio-economic factors } \\
\hline \multicolumn{5}{|l|}{ Income status } \\
\hline High & 1.00 & 1.00 & 1.00 & 1.00 \\
\hline Middle & $1.21(1.02 \sim 1.43)^{*}$ & $1.23(1.04 \sim 1.45)^{*}$ & $1.08(0.90 \sim 1.29)^{\mathrm{NS}}$ & $1.06(0.88 \sim 1.27)^{\mathrm{NS}}$ \\
\hline Low & $2.00(1.44 \sim 2.79)^{* * *}$ & $2.20(1.57 \sim 3.08)^{* * *}$ & $1.35(0.94 \sim 1.94)^{\mathrm{NS}}$ & $1.43(1.00 \sim 2.05)^{\mathrm{NS}}$ \\
\hline \multicolumn{5}{|l|}{ Oral Health Behavior factor } \\
\hline \multicolumn{5}{|c|}{ Toothbrushing after lunch time } \\
\hline 5 or more times $(/ w k)$ & - & 1.00 & - & 1.00 \\
\hline 4 times and less (/wk) & & $1.19(1.02 \sim 1.40)^{*}$ & & $1.20(1.01 \sim 1.42)^{*}$ \\
\hline \multicolumn{5}{|c|}{ Drinking carbonated beverage } \\
\hline 2 times and less (/wk) & - & 1.00 & - & - \\
\hline 3 or more times $(/ \mathrm{wk})$ & & $1.24(0.93 \sim 1.67)^{\mathrm{NS}}$ & & \\
\hline \multicolumn{5}{|l|}{ Eating confectionary } \\
\hline 2 times and less (/wk) & - & 1.00 & - & 1.00 \\
\hline 3 or more times $(/ \mathrm{wk})$ & & $1.38(1.16 \sim 1.64)^{* * *}$ & & $1.36(1.14 \sim 1.63)^{* *}$ \\
\hline \multicolumn{5}{|l|}{ Psychological factors } \\
\hline Perceived stress & - & - & $2.13(1.74 \sim 2.60)^{* * *}$ & $2.22(1.82 \sim 2.71)^{* * *}$ \\
\hline perceived self-esteem & - & - & $0.89(0.78 \sim 1.01)^{\mathrm{NS}}$ & \\
\hline Family support & - & - & $0.90(0.77 \sim 1.04)^{\mathrm{NS}}$ & \\
\hline Friend support & - & - & $0.87(0.76 \sim 1.00)^{\mathrm{NS}}$ & $0.82(0.72 \sim 0.93)^{* *}$ \\
\hline
\end{tabular}

By multi-variable logistic regression.

${ }^{*} \mathrm{p}<0.05,{ }^{* *} \mathrm{p}<0.01,{ }^{* * *} \mathrm{p}<0.001,{ }^{\mathrm{NS}} \mathrm{p}>0.05$. 
consumption of chocolate and sweets, stress, and support from friends were found to have significant effects on the experience of oral symptoms. In particular, as the level of perceived stress increased, the risk for experiencing oral symptoms increased 2.22-fold ( $\mathrm{p}<0.001)$.

\section{Discussion}

The school-age period is an important time during which a child undergoes not only physical development but also social and psychological development, as the child forms relationships with other children of similar age and develops a self-concept ${ }^{17)}$. It is also a period in which psychological problems such as stress and depression arise due to school, academics, problems with friends, and school violence ${ }^{18,19)}$, and most school-aged children lack the ability to cope with these psychological challenges ${ }^{20)}$. It has been confirmed in the published literature that a child's oral health is affected not only by socioeconomic and oral health behavioral factors at the personal level but also by various ecological factors, including psychological factors and environmental factors at family and community levels ${ }^{21-23)}$. The goal of the present study was to investigate the effects of socioeconomic, oral health behavioral, and psychological factors on children's subjective experience of oral symptoms, using data of the Korean Youth Health Survey (2010).

In this study, $46.5 \%$ of all children experienced more than one oral symptom, and those with low subjective income levels experienced more symptoms. The adjusted OR for experiencing oral symptoms was 1.36 times greater for children who consumed cariogenic foods, such as chocolate and sweets. This result is consistent with a study by $\mathrm{Jang}^{24)}$ in which the rate of permanent dental caries was low and the level of subjective oral health status was high among participants who had developed healthy eating habits. Consumption of food products containing sugar is a major risk factor that not only affects oral health but also systemic health and can cause obesity. For this reason, nutrition education using school lunch as a medium must not only include education on how to read a nutrition facts table but also information about sugar consumption, to help children form healthy eating habits.
Given the recent recommendation by the World Health Organization (WHO) that daily sugar intake should be reduced from $10 \%$ to $5 \%$ of the total caloric intake ${ }^{25)}$, integrated education on nutrition, oral health, and systemic health is warranted, to help people develop appropriate eating habits from childhood. In addition, during visits to a dental clinic or hospital, children with confirmed oral problems should be queried on how frequently they consume foods containing sugar, and they should be provided with dietary consultations and education routinely. The home environment plays an important role in the development of a child's eating habits. This has been confirmed in a previous study, which found that the higher the mother's level of oral health care knowledge, the lower the child's number of days of restricted activity. Therefore, parents' beliefs about oral health behaviors had a significant influence on children's oral health ${ }^{26)}$. Such a finding shows the need for school programs that are not solely focused on educating children but also aim to help children to maintain at home the healthy eating habits learned at school, via education on eating habits and oral health care that requires parental participation. Methods to create a supportive environment for children to carry out healthy behaviors at home (e.g., sending school newsletters with information related to oral health care) must also be explored.

Among the psychological factors investigated in this study, support from friends and the level of perceived stress significantly affected the risk of experiencing oral symptoms. The higher the support of a friend, the more likely it is to experience subjective oral symptoms by 0.82 fold. This result was consistent with a study by Shin et al. ${ }^{27)}$ in which the proportion of students who did not brush their teeth after lunch at school gradually increased over a period of 12 months, despite implementation of tooth brushing classes. Students did not brush their teeth because they felt too lazy to carry a toothbrush and toothpaste around and because their friends did not brush their teeth. This demonstrated that support from friends is an important motivator of children's healthy behaviors. In this study, the OR for experiencing oral symptoms increased 2.2-fold as the level of perceived stress increased. This result was consistent with Shin's study ${ }^{10)}$ that 
investigated the association between stress and oral health status among elementary students from particular regions of Korea. In addition, Park et al. ${ }^{28)}$ studied the correlation between stress and health problems and observed high levels of academic stress among elementary school students. These authors also found that the higher the level of stress experienced, the higher the risk for health problems such as headache, stomachache, and hypersensitivity. The results of the present study were also consistent with those of $\mathrm{Kim}$ and $\mathrm{Han}^{29}$, which reported that as the level of stress related to university admission increased, levels of perceived symptoms of temporomandibular disorder, intraoral disease, mouth dryness, dental caries, and periodontal disease also increased.

School-aged children exhibit prosocial behaviors that positively affect their friends as they form positive relationships at school, a place where they spend most of their day. In turn, children are also motivated to be prosocial by friends who exhibit prosocial behaviors ${ }^{30)}$. Considering that children's oral health behaviors are significantly affected by the support of friends, it is necessary to provide children with a supportive environment in which they are encouraged to practice oral health behaviors. The WHO has proposed a school health-promotion model that is aimed at improving health and preventing disease among all members of school communities $^{31)}$. This model takes a cooperative approach to creating an environment in which school students, teachers, and staff members engage in health behaviors that create a healthy culture. School community members also receive systematic and comprehensive school health care services by including health-related content in the education curriculum. It is necessary to develop comprehensive health care programs based on this model to improve children's physical health (including oral health) and psychological health, and to create a culture and environment within schools that encourages students to adopt healthy behaviors.

In some provinces of Korea, demonstration projects based on school health-promotion models have been implemented with the aim of improving school health systems and students' health behaviors. These programs seek to remove health risk factors that affect school members, improve physical and social environments, and provide health education and health care services, in collaboration with schools and health centers. These projects have been shown to improve people's skills in managing their own physical health and also to positively affect their psychological health by improving self-esteem, learning ability, and peer relationships while reducing problematic behaviors ${ }^{32}$. However, the oral health-related content included in these programs consists of oral health care education and tooth brushing practice that altogether last about an hour, and are thus only a small part of the project. A comprehensive school health-promotion program with extended content on oral health must be added to existing school health initiatives. In addition, changes must be made to current health education curricula at schools (e.g., develop curricula for health education courses) to promote intellectual, physical, and psychological health among students.

The abovementioned results have been observed not only among children but also among adolescents, in whom stress from academic activities and a lack of leisure activities were found to significantly affect the rate of having social problems, such as with friendships, and depression $^{33)}$. Ultimately, to improve oral health among children and adolescents, the existing health education curricula must be reformed in such a way that students are encouraged to manage their own oral health starting from elementary school age and continuing throughout the high school years, during which period the level of stress related to university admission is very high. This is a need to develop comprehensive health education curricula in which content on systemic health, nutrition, smoking cessation, and oral health are intimately connected, as well as multilateral interventions and programs that consider psychosocial factors in different time periods.

The present study had a number of limitations. First, we did not consider the effects of various oral health behaviors and psychological factors on the subjective experience of oral symptoms using secondary dataset. Second, we used information about oral symptoms, income levels, and other parameters that were subjective and self-reported by the students. Third, because the original data did not provide strata, clusters, and sampling 
weights, we could not perform an analysis using a complex sampling design despite the fact that stratified cluster sampling was used. However, this study is important in that we identified factors that affect subjective experience of oral symptoms, using data from a national survey and a systematic sampling method to obtain a sample that is representative of the population of children in Korea. By further breaking down psychological factors related to children into even more specific factors and identifying their associations with children's oral health, we were able to provide basic research material that will be useful in the development of oral health promotion systems and policies for children. Longitudinal research using data of objective oral health conditions, socioeconomic indices, and so on must be conducted in the future.

\section{References}

1. Sheiham A, Moysés SJ, Watt RG, Bönecker M: Promoting children's oral health-theory \& practice. 2nd ed. Quintessence editora, Sao Paulo, pp.177-178, 2006.

2. Ministry of Health and Welfare: 2012 Korean national oral health survey: II. Survey results. Ministry of Health and Welfare, Sejong, pp.292-299, 2013.

3. WHO Oral Health Country/Area Profile Programme: WHO Collaborating Centre. Retrieved February 3, 2015, from http://www.mah.se/CAPP/Country-Oral-Health-Profiles/Acc ording-to-Alphabetical/.

4. Selwitz RH, Ismail AI, Pitts NB: Dental caries. Lancet 369: 51-59, 2007.

5. Fisher-Owens SA, Gansky SA, Platt LJ, et al.: Influences on children's oral health: a conceptual model. Pediatrics 120: e510-e520, 2007.

6. Weintraub JA: Family matters: influence of biology and behavior on oral health. N Y State Dent J 73: 14-19, 2007.

7. Kim MS: The subjective well-being of Korean children and its policy implications. Health Welf Policy Forum 220: 14-26, 2015.

8. Retrieved September 20, 2016, from https://www.edujikim. com/customercenter/board/default/view_b.asp?intBbsSeq $=8$ $\&$ Page $=1 \&$ intArticleSeq=97551(2014).

9. Duncan GJ, Boisjoly J, Harris KM: Sibling, peer, neighbor, and schoolmate correlations as indicators of the importance of context for adolescent development. Demography 38: 437-447, 2001.

10. Shin BM: Association between stress, oral health behavior and oral health status among 6th grade primary school students in Gangneung city. J Korean Acad Oral Health 34: 403-410, 2010.

11. Park HJ, Kim HW, Ko SY, Lee JH: Moderating effects of oral health behaviors on the relation between daily stress and oral health status in Korean adolescents. Korean Public Health Res 41: 81-93, 2015.

12. Jung YY: A study of the relation of stress to oral hea1th-related of life in male high school students of Chungnam. J Dent Hyg Sci 14: 158-166, 2014.

13. Kwon HJ, Yoon MS: Relationship of depression, stress, and self-esteem with oral health-related quality of life of middle-aged women. J Dent Hyg Sci 15: 825-835, 2015.

14. Lee SL, Kwag JS, Choi JH: Correlation and influencing factors on oral health awareness, oral health behavior, self-esteem and OHIP-14 in childcare teachers. J Dent Hyg Sci 15: 261-269, 2015.

15. Choi IJ, Lee KB, Kim HJ, et al.: Korean youth indicator survey V: health and safety(protection). National Youth Policy Institute, Sejong, pp.255-270, 2010.

16. Murry JW, Hammons JO: Delphi: a versatile methodology for conducting qualitative research. Rev High Educ 18: 423-436, 1995.

17. Rhee O, Hyun OK, Choi BG, Lee KO, Lee S, Cho SY: Addressing the development of Korean children \& a cohort study of parenting and parent-child relations. J Korean Counc Child Rights 6: 385-414, 2002.

18. Lee YO, Lee JS: A study of the difference by development stages on daily stress, perceived environment, psychological problem of child/adolescents. Korean J Child Psychother 6: 53-79, 2011.

19. Achenbach TM, McConaughy SH, Howell CT: Child/adolescent behavioral and emotional problems: implications of cross-informant correlations for situational specificity. Psychol Bull 101: 213-232, 1987.

20. Park SO, Lee JS: Compare with gifted and general children: A study on children's stress and coping behavior. J Future Early Child Educ 10: 225-245, 2003.

21. Jung SH: New dental public health. 1st ed. Komoonsa, Seoul, 
pp.30-36, 2012.

22. Marcenes WS, Sheiham A: The relationship between work stress and oral health status. Soc Sci Med 35: 1511-1520, 1992.

23. Hilgert JB, Hugo FN, Bandeira DR, Bozzetti MC: Stress, cortisol, and periodontitis in a population aged 50 years and over. J Dent Res 85: 324-328, 2006.

24. Jang JH: The relationship of diet habits, obesity and level of oral health among elementary school children. J Korean Soc Dent Hyg 8: 229-240, 2008.

25. World Health Organization: Guideline: sugars intake for adults and children. WHO Document Production Services, Geneva, p.16, 2015.

26. Kim SN, Lee HS, Kim KH, Kim DE, Park DH: Factors affecting children's dental utilization: an application of the Andersen model. J Korean Acad Pediatr Dent 25: 162-170, 1998.

27. Shin SJ, Shin BM, Bae SM: A case study on implementation of a school-based tooth brushing program in Gangneung city,
Korea. J Dent Hyg Sci 13: 518-527, 2013.

28. Park MY, Pyo KS, Ryu SY: A study on the stress and health problem in some primary school children. Med J Chosun Univ 27: 57-67, 2002.

29. Kim SR, Han SJ: The relationship between perceived oral health status and entrance exam stress levels in high school students. J Dent Hyg Sci 15: 509-517, 2015.

30. Laura EB: Child development. 7th ed. Sigma Press, Seoul, pp.496-497, 2008.

31. World Health Organization: Health promoting schools: a framework for action. World Health Organization Western Pacific Region, Manila, pp.3-15, 2009.

32. Seongdonggu Community Health Center: Healthy school project. Seongdonggu Community Health Center, Seoul, pp.3-86, 2006.

33. Lee MR: Effects of adolescent stress and psychological states during daily activities on depression. J Future Oriented Youth Soc 13: 47-67, 2016. 